\title{
Analysis on the Teaching of Latin Dance for Office Workers
}

\author{
Yong $\mathrm{Xu}$ \\ Wuhan Business University \\ Wuhan, China 430050
}

\author{
Yazhen Li \\ Wuhan Sports University \\ Wuhan, China 430070
}

\author{
Jingwen Zhou \\ Wuhan College \\ Wuhan, China 430212
}

\begin{abstract}
With the development of modern society, Latin dance has become increasingly close to ordinary people and has gradually become a fitness sport. According to the mode of thinking, imagination and psychological characteristics of contemporary office workers, as well as the characteristics of Latin dance, the research and discussion on teaching and the training methods in sports dance teaching, this paper proposes how to use teaching methods in Latin dance classes for office workers in order to achieve the teaching goals, at the same time, how it can be accepted by social people who are different from college students. What's more, in order to improve learners' aesthetic quality and their own qualities, it is particularly important to cultivate aesthetic values in physical education. As a result, it can make up for the deficiencies in the current Latin dance education. The shortcomings of education in the traditional exams should be put aside to stimulate the interest of office workers in learning Latin dance and to better realize the task of Latin dance teaching for office workers. Based on the indepth analysis of the traditional dance teaching model, this paper finds out the disadvantages of the traditional dance teaching and integrates the cultivation of appreciation and aesthetics into the new teaching method, so as to make the Latin dance education more effective to the working people.
\end{abstract}

Keywords-sports dance; office worker; teaching; training; aesthetic; interest cultivation

\section{INTRODUCTION}

With the continuous improvement of material life in modern society, Latin dance has attracted wide attention, especially those of women. The office workers pay great attention to the pursuit of strong and handsome physique, graceful and dignified posture, symmetrical and harmonious body, and unrestrained demeanor. The pursuit of beauty is the content given by The Times to Latin dance education, and it is the psychological needs of people. Sports dance, which integrates physical beauty, music beauty and costume beauty, can endow office workers with various aesthetic psychological effects while exercising. Thus, spiritual purification, cultivation of sentiment, mental pleasure and emotional sublimation can be achieved. Meanwhile, Latin dance is a rigorous stylistic activity, which can enrich the cultural life of these adults and has certain practical value. Most of office workers have already passed development stage, so all sorts of body functions begin to decline. Although the process is slow, yet can it be avoided. In addition, the office workers are under great pressure and most of their lives are irregular, so they need a kind of exercise to improve their physical quality and keep healthy. Their physical health during this period may affect the rest of their life. Latin dance, as a kind of sports, can effectively improve the interest of office workers. In entertainment, people also have a highly self-conscious in fitness, so the amount of exercise and intensity will be guaranteed, and the psychological quality of office workers will be improved. This can effectively ensure their physical and mental health needs and the cultivation of their lifelong sports habits.

\section{A. Purpose and Significance of the Study}

Now more and more office workers begin to understand Latin dance and recognize Latin dance as a good fitness and communication activity. They start to look for places to learn Latin dance. However, the purpose of learning Latin dance for office workers is different from other groups, and they will also be affected by time, physical condition and other aspects. They cannot be taught and trained like teenagers, thus a suitable way should be explored to teach them. And this article is to try to find a common way of teaching and training for most office workers. Nowadays, Latin dance has become a very mature fitness program and communication program in foreign countries. It is also very popular in Taiwan of China. We can see many famous artists showing their dancing skills in many TV shows. But in mainland China, Latin dance has only just begun as a fitness program. Many parents have let their children start learning, so the teaching of Latin and adolescent Latin is much more perfect. Many colleges offer this major, and the teaching methods are systematic. However, there are not many professionals who design special teaching and training methods for them, so it is necessary to carry out research and development in this field.

Latin dance is a good fitness and communication activity. However, the purpose of learning Latin dance of office workers is different from other groups, and they will also be 
affected by time, physical condition and other aspects. They cannot be taught and trained like teenagers, thus a more suitable way is needed to be explored to teach them. And this raises new questions. Its core is to break the old teaching model, highlight the characteristics of adult teaching, reform teaching methods, combine with the reality of students, improve teaching content and improve teaching quality. And the author just wants to try to find a way of teaching and training that is common to most office workers.

\section{B. Research Status at Home and Abroad}

1) Development status abroad: The sports dance (international standard ballroom dance) developed from the original ballroom dance. Ballroom dancing originated in Europe and the United States in the 17th and 18th centuries and it is a kind of casual entertainment dance. In 1925, the royal society of dance has been established and the royal teachers of the United Kingdom hired first-class experts to standardize the movements and then the international standard ballroom dance was promulgated.

As early as the 1920s, the United States began to offer it bachelor's and master's degrees, and in 1940s it had a doctor's degree. Therefore, the United States has an early start in the dance education popularization.

British dance education has three modes: one is the professional actor education, which is mainly engaged in ballet and contemporary dance. One is to train dance teachers and takes ballet, modern dance, folk dance, dance history theory, music and drama as the main courses. It is a comprehensive talent training model of university dance education. The content of what students learn is relatively broad and has certain scientific nature and rationality. Compared with the same kind teaching model, it is a relatively perfect construction system for the education of a dance teacher. There is also a kind of sports dance, namely the popularizing education. Its courses give priority to international standard dance. Students who participate in the examination organized by the National Dance Teachers Association can obtain teacher certificates of different levels respectively, and those who pass the examination can undertake teaching work of national standard dance at different levels.

In France, there are four forms of dance education: Professional dance education, professional education of dance, preschool dance education, higher level dance education. These four forms of dance education are linked to each other and linked together. From a macroscopic perspective, they are a relatively complete dance education system.

2) Domestic development status: Sports dance was introduced to China in the late 1980s, and in the early 1990s, the General Administration of Sport of China has established the Sports Dance Association (group organization). In 1993, the first national sports dance championship was held in Wuhan. Since then, it has been held once a year, and now it has been held 20 times. Due to the chaos of the management of the association and the obvious bias in the direction of work guidance, serious violations of the competition organization have caused some social corruption and even violent incidents to flood this elegant sport, seriously hurting the enthusiasm of some coaches, athletes and the general public. In 2001, the social sports guidance center of the General Administration of Sport of China reformed the leading body of the sports dance association, and promulgated various management regulations, which integrated the development of sports dance into the legal track.

In recent years, many high schools have set up physical dance teaching courses, which are deeply loved by college students. Among the 16 sports departments in China, half of the colleges and universities have opened specialized courses in sports dance. Every year, Beijing Sports University has special enrollment of sports and dance majors, and regularly participates in sport dance competitions of national college students. At the same time, there are general physical dance courses, compulsory courses and specialized courses. In 1994, the National Taiwan Sports Academy, located in Taichung city, opened a dance group under the department of physical dance. For the first time, Taichung district has its own formal dance cradle. In the same year, it enrolled the first dance majors on the island. In the early summer of 1995, the school established a dance department and for the first time enrolled 40 dance students independently. Since the fall of 1996, the dance school has been upgraded to an academy and has been promoted simultaneously to a dance department, though the 5year intermediate dance department has been parallel to the 4year university dance department.

\section{RESEARCH OBJECTS AND RESEARCH METHODS}

\section{A. Research Objects}

Forty-three students from a club in Qingdao learn Latin dance class.

\section{B. Research Methods}

1) Documental method: According to the research purpose of this project, the author has consulted relevant materials, books and magazines in school libraries and Qingdao city libraries. As a result, the author has gained a comprehensive and correct understanding of relevant knowledge and materials, and has made a comparison with the actual materials, so as to gain an understanding of the general direction of this project.

2) Field investigation method: Through the field investigation of several clubs in Qingdao city, the author got some practical information, and chose to make a key investigation of one of them. The author recorded while analyzing, trying to grasp some characteristics of the target.

3) Logical analysis: Collect the data and the information obtained from the field investigation and make overall analysis.

\section{RESEARCH RESULTS AND ANALYSIS}

\section{A. The Meaning of Latin Dance}

Latin dance is a kind of walking style dance with men and women as partners under the guidance of dance music with a 
specific rhythm and uses dance techniques to demonstrate the style and charm of dance. With the accompaniment of happy and beautiful music, learners will dance with their partners to their heart's content, which will help to relax their mind and body, eliminate fatigue, gradually form a good awareness and habit of communicating with others, and gradually change their characters. Moreover, it can have an impact on the aesthetic value of learning dancers and make them get allround development in a pleasant and relaxed atmosphere. Latin dance is a comprehensive project with high aesthetic value and fitness and entertainment value. It is a new sports project integrating sports, music, dance and costume. It expresses people's health, strength, appearance and physical beauty through various body movements. The beauty of Latin dance and the need of people to appreciate it will certainly raise its status to a certain height and make it a fashionable, elegant and popular sport.

\section{B. Main Tasks of Latin Dance Teaching}

The main task of Latin dance teaching is to let the dancers understand the time background and current development situation of Latin dance, master the basic skills and combination of Latin dance. On such basis, it gives some of the dancer strong abilities to learn competitive Latin dance, so that they can participate in various competitions. Other aims are to cultivate their good posture and their sentiment, to promote the communication between classmates and social communication ability, to cultivate the ability to appreciate the beauty and the appreciation of dancers, and to improve their own culture, so as to achieve the goal of lifelong sports. How can Latin dance achieve better teaching effect through education? How to correctly express the teaching method of Latin dance to ensure all dancers can accept, so that the teaching effect can reach the best? I think that's the difficult and important part. In my opinion, Latin dance class is not just about teaching step, but also about combining all aspects of dance learners. Learning Latin dance is an aspect, and more importantly, it is to please the feeling, to enhance aesthetic concept and to exercise their physical qualities. The application of music in Latin dance teaching can improve the excitement of learning dancer's nerve center and activate the classroom atmosphere, enhance their learning enthusiasm, enhance their physique, edify sentiment, and cultivate their feeling of beauty and make the movements of dancers more beautiful. This is of great significance to improve the aesthetic ability of dancers and their correct understanding of beauty, enhance the sense of rhythm, improve the effect of classroom practice, delay the generation of fatigue and education of beauty. As we can see, there are many aspects to teach in a Latin dance class, so we should not only focus on the dance but also extend to a wider level. Of course, these are my personal views on the teaching of Latin dance in colleges and young people, and now we are dealing with a group of adults, and we can't just think of them as students. Because they are different from ordinary students, they have fundamental differences in their demands compared with the aforementioned college students and teenagers. As a result, it is impossible to use the traditional teaching model. Of course, it's not that the traditional teaching method is useless, just because there are many drawbacks in the traditional teaching mode in this field. Therefore, I think the teaching for adults and those working people should mainly focus on their sense of pleasure.

\section{Latin Dance Teaching Methods for Office Workers}

1) Adjusting measures according to local conditions: The teaching material of Latin dance for office workers is very important. It can not only imitate professional colleges and universities but deviate from the reality of adults. In that case, it will blindly demand high standards without paying attention to the situation of office workers which will only make learning and teaching dancers difficult. According to the physical and psychological characteristics of office workers, we should "learn from their strengths to make up for their weaknesses" and "tailor their clothes according to their own needs" and establish a teaching mode of mutual communication. According to the current situation, Latin dance teaching for office workers is a healthy education, popular education and exploratory education. Therefore, we should first establish their own teaching position according to the characteristics of working people and create a teaching mode suitable for their physical and mental conditions. Characteristics of working people: First, the age of these people is relatively large, the growth and development of the body is basically stereotyped, few has a good waist and leg flexibility. Jumping ability can only be regarded as satisfactory. For some technical movements, it is difficult for them to complete even with 200 percent efforts. Second, their social experience is obviously and relatively rich. In respect of the human affairs, they are experienced and wise, but also have very prominent personality. The third is that they have a serious lack of confidence and have high self-esteem. They do not want teachers to point out their mistakes in front of everyone. Fourth, most people don't have any dance theories at all. They have an obviously weak ability in memorizing and there is no theoretical basis to help them understand. But they have a strong ability to analyze and solve problems, far better than students in school. They know that things will change when it developed to an extreme and after the changes can things go smooth. They have a strong imitation ability and a high thirst for knowledge. Some are very enthusiastic, some are very hard-working, which is the physical status of office working learners and some common psychological characteristics. Therefore, in view of these characteristics, teachers should make more use of rumba dance in teaching materials. Known as the mother of Latin dance, Lombard has distinct national style and local characteristics. It has a broad wide of supporters, many of whom learned about Latin dance only through rumba, and some of them even thought that rumba was exactly Latin dance before learning Latin dance. As the main teaching material of Latin dance for office workers, it is easy to be accepted by students, and also easy to arouse students' interest in learning. In the teaching process of Latin dance for office workers, it is very important to select the teaching content suitable for them from various Latin 
dance textbooks. In order to obtain the ideal teaching effect, we must make efforts from the following aspects: First, we should set foot on the reality, do not get out of touch with The Times, and develop innovative ideas. Latin dances of different types and different technical difficulties should be created according to the age, physical condition, zero basis conditions and acceptance ability of the office workers. In the process of choreography and creation, the dance must reflect the contemporary atmosphere and rich dance connotation. The second is to learn from the Latin dance teaching content of professional colleges. But the idea of borrowing is not to let us copy the original ones, but to absorb the essence, rather than to show the "take-ism" in this process. In the selection of teaching content, teachers must combine the actual situation of office workers to screen, sort out and process the teaching content to endow it with teaching value, practical value and performance value, so as to achieve better teaching effect. Third, select excellent dance works that are easy to understand and imitate from those choreographed and created by some famous artists, analyze them carefully, fully understand the emotional connotations of the works, and teach them to the students, so as to improve the understanding of dance culture of the students. It is also a great way to improve their theoretical knowledge and help them understand Latin dance actions. Sometimes Latin dance, like mathematics, can only be better remembered and expressed when it is understood. As the old Chinese saying goes, only when you see it, can you realize it.

2) Teaching according to aptitude: The selection of teaching methods and teaching forms should also be improved gradually around the characteristics of office working Latin learners, so as to break the old teaching mode and highlight the characteristics of Latin dance teaching for office workers. This feature should not only be different from Latin dance teaching for teenagers, but also should be distinguished from general adult teaching. After all, general adult teaching includes some middle-aged and old people and some successful people. Sometimes there are big differences in teaching people with different status. Said Zhu Xi, a famous scholar in ancient China, "things can only be achieved with certain methods. A good teacher cannot teach without good methods and a good student cannot learn without good ways." It can be seen that the role of teaching methods is very important. Latin dance, as an independent dance, not only has the general rule of common dance teaching, but also has its own teaching particularity.

In teaching, teachers must adopt the method of combining theory with practice to solve the particularity of students. In order to explain and demonstrate the dance movements, the teacher can tell a little about the history and culture behind the movements but talk more about the norms and requirements of the movements, so as to inspire students' understanding ability. Therefore, when teaching each type of Latin dance, teachers should not teach students many background materials of the dance, which is the knowledge that students in the professional class should learn. Although letting students understand the cultural background of the dance can better enable them to grasp and show the style of the dance, students will suddenly feel bored with too much knowledge in this aspect. There is nothing wrong with broadening a student's knowledge. However, they come to this place for activities and other purposes but never want to stand here and listen to lectures. Because of the characteristics of Latin dance curriculum, it is decided that dance teaching must follow the teaching principle from single movement to combined actions. Therefore, according to the actual situation of students, they are divided into the first class, the intermediate class and the advanced class. Teaching methods such as demonstration method, explanation method, decomposition method, integrity method and practice method should be adopted, and the physical and mental characteristics and aesthetic taste of office workers should be combined into the dance education. Teaching should be carried out in accordance with the principle of being practical, gradual, systematic, scientific and interesting.

3) Dance with emotion: Emotion is the starting point of Latin dance, and any kind of Latin dance cannot leave emotion elements. In the teaching of Latin dance for office workers, we should not just see the professional dance movements but ignore the brewing of dance emotions. Many students think that they are not professional dancers and they are not young. Why should they pursue such standard movements? They are satisfied as long as they can perform several routines. This makes some learners only satisfied with memorizing the movements but ignore the charm of Latin dance itself. On this issue, it is necessary for teachers to improve their teaching methods. In addition to seizing the advantage of strong understanding ability of adults, it is necessary to inspire them to build images based on emotion, so as to achieve "dancing with emotion". At the same time, attention should also be paid to the cultivation of adult observation ability, so that they can imagine more plots in the dance. In this way, the emotion and movement can be integrated, so as to achieve the effects of "conveying emotions and ideas".

Fair-sounding and proper music is the precondition of "dancing with emotion and expressing emotion". Teachers should screen music according to the characteristics of office workers. First, it should have a strong sense of rhythm. For the working students, most of them do not have received professional music training, they even don't listen to dance music. They have poor sense of rhythm and cannot catch the rhythm of music without obvious pauses. Secondly, music with style and strong representativeness should be selected. In this way, students can combine their movements with music and understand the style of dancing more quickly. Third, we should choose modern songs. Music, which is accompanied by some songs that have been sung for a long time, can enhance students' interest in learning. After all, music has withstood the test of time and proved that they can be liked by most people, making it convenient for students to memorize dance movements and enhance their performance. Therefore, in teaching practice, teachers should use various methods to guide students to give actions with emotion to perform the connotation. In this way, students can fully understand the 
meaning of dance movements and understand dance vocabulary and the emotions of the music.

4) Being people-oriented: Office workers dancers come from all walks of life. Don't assume that they are all whitecollar workers. Among them are teachers, civil servants, doctors, bank clerks, businessman, soldiers, policemen and the normal working people. We're dealing with the public. There are rarely successful people showing up in the dance class that I'm talking about. However, the targeted group is still wide. They learn Latin dance for the purpose of exercising, making friends and living a full life. They come from different social classes, and there is a big difference in ages, personality, physical quality, and educational level. Their purposes of learning Latin dance are also different from each other. Some of them are young and have learned dancing when they were young. So they have a strong ability of understanding. They hope to learn some difficult Latin dance routines so that they can dance in front of the public as soon as possible. Some are older, and learning Latin is for physical exercise. They have no requirement to improve the level of dance. Some of the students also want to have regular and progressive dance classes like the professional ones. These gaps become the difficulties for teachers to organize teaching methods. If students' learning attitudes and thoughts are not unified, conflicts will easily arise, which will affect the teaching effect and learning atmosphere. Therefore, in the teaching process, teachers should pay attention to cultivating students' collective ideas, emphasizing mutual help and common progress. At the same time, the teaching progress should be appropriately adjusted so that the older students can keep up with the rest students while the younger students will not be bored. The enthusiasm and learning interest of each student will then be aroused.

5) Problems in learning latin dance for office workers:Limitations of requiring a fixed partner. It requires relatively (and certainly not absolutely) fixed partners, which is its biggest limitation. Fixed partner needs a long time to form a stable tacit understanding and reach a high level of dance. Office workers have a lot of interest, so there aren't many people who really have fixed practice hours, let alone two people with the same fixed time. Many people give up studying Latin because they can't find a suitable partner.

Limitations of high costs. It would cost a lot to actually see effects. Since they are office workers, most of them must be at the working class. Most of them have their own families, and more money will be spent on their families. People who really like them need to find high-level teachers to guide them, which is quite expensive. It is difficult for the average person to bear these expenses. For amateurs, learning to dance is not a necessity, especially for those who do not appreciate the benefits of Latin dance, or even are biased against it.

Limitations of time and places. Latin dance cannot be learned in a day. It requires a long and persistent effort from the basic skills. Moreover, the requirements for the places are relatively high. There should be at least 200 square meters of venues, and not too many people are required to dance together in this venue. This limitation applies to everyone, not just office workers, but to people in school, training classes or clubs.

Limitations of persistence. When people first started learning, it was hard and they couldn't hold on to it. Office workers have their own jobs and cannot spend a lot of energy on a hobby. Quite a few people have a high interest in learning dancing at the beginning and think that they can learn it easily. But when they really learn it, they find it hard to stick to it.

\section{CONCLUSIONS AND SUGGESTIONS}

\section{A. Conclusions}

1. The entry-level office workers only seek quantity and progress, but do not pay attention to the quality of their actions. However, the differences in learning objectives make them cannot be over-demanded in the solid foundation.

2. Each student is liable to fall into the mistake of measuring his dancing skills by "how many steps he takes" at the beginning. They only purse how many steps he takes. But because the body condition of office workers and their fundamental conditions, they cannot learn highly difficult steps.

3. Postures should be emphasized. Office workers should pay attention to the beauty of posture when they are learning the Modern or Latin dance. The unflappable and elegant posture makes the dancer's spirit high and their dancing pleasant to enjoy.

4. Make the process as easy as possible. Some people, when they began to learn Latin dance, fell into it on the spur of the moment. They thought it was a pleasure to learn it but do not know that relaxation and cheerfulness comes from hard word and great practice.

5. Music cannot be ignored. At the beginning of study, office workers usually only pay attention to the learning of technical actions and lack the understanding of the music. In learning, there is often a disconnection between actions and accompaniment music.

6. Due to a variety of health hazards or occupational diseases caused by sitting for a long time, office workers are unable to do various movements when learning Latin dance.

\section{B. Suggestions}

1. On the basis of not affecting the beauty of the movement, we should try to be as tolerant as possible. Therefore, in learning the actions, although it needs to be carefully and gradually studied, it should also be appropriate.

2. To some extent their learning is a kind of "quick success", which requires teachers to reduce the difficulty of the steps or decomposing the steps and selecting some to teach. We should observe their foundation, and then selectively help them learn some steps according to their characteristics, so as to achieve "icing on the cake".

3. Always keep your head up, chest out, abdomen closed, waist up, shoulders flat, knees relaxed, thighs and hips 
clamped and lifted while dancing. This part is not difficult, and more requirements should be made. Most of the office worker learners also study for such purposes.

4. It should be pointed out that it is counterproductive to study if office workers come to study with a bad attitude. But you have to take their practical situations into account and you can't train them as professional learners. The training dose of each class can be reduced to lengthen the learning period of the movement.

5. In the teaching process, we must pay attention to mobilize their emotions. When teaching sports dance, we should strengthen their music knowledge. This can also make them happy and achieve their purpose of coming here to relax.

6. Before the formal Latin dance teaching, do some healthy exercises to help office workers' occupational diseases recover. On the one hand, it will contribute to the health of these office workers, on the other hand, it will also help Latin dance teaching in the future.

\section{REFERENCES}

[1] Zhao li. Development Status and Countermeasures of Sports Dance in China [Dissertation] 2003.

[2] Liu Jingyu. On Aesthetic Education in Sports Dance[J]. Sports science, 2002, (3).

[3] Su Wenqing. Research on the Connotation Cultivation of "spirit, tolerance and expression " in Sports Dance [D]. Wuhan Institute of Sports, 2012.

[4] Wen Yi. Theoretical Research on Personalized Teaching Model of Sports Dance [D]. Wuhan Sports University, 2012.

[5] Xu Li. Investigation on the Status and Countermeasures of Sports Dance Development in Anhui Province [D]. Anhui Normal University, 2006.

[6] Shangguan Lai. Theoretical Research on the Teaching Ability Structure of Sports Dance [D]. Wuhan Sports University, 2006. 